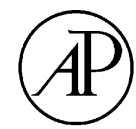

ACADEMIC

PRESS

\title{
Studies of inclusion complexes between cyclodextrins and polyazamacrocyclic chelates of lanthanide (III) ions
}

\author{
Elsa S. Henriques a , Margarida Bastos ${ }^{b, *}$, \\ Carlos F.G.C. Geraldes ${ }^{\mathrm{c}}$, Maria João Ramos ${ }^{\mathrm{a}}$ \\ a Requimte, Departamento de Química, Faculdade de Ciências, Universidade do Porto, \\ Rua do Campo Alegre, 687, 4169-007 Porto, Portugal \\ b CIQ/Departamento de Química, Faculdade de Ciências, Universidade do Porto, \\ Rua do Campo Alegre, 687, 4169-007 Porto, Portugal \\ c CNClDepartamento de Bioquímica, Faculdade de Ciências e Tecnologia, \\ Universidade de Coimbra, Apartado 3126, 3000 Coimbra, Portugal
}

Received 3 April 2003; accepted 15 July 2003

\begin{abstract}
The complexes between $\gamma$-cyclodextrin and lanthanide (III) chelates of the polyazamacrocycles DOTA (DOTA $\equiv 1,4,7,10$-tertraazacyclododecane-1,4,7,10-tetraacetate) and DOTP (DOTP $\equiv 1,4,7,10$-tetraazacyclododecane-1,4,7,10-tetramethylenephosphonate) have been thought out to enhance the potential of such chelates as contrast agents for MRI. Given the actual demand for the design of new contrast agents, we thought it worthwhile to confirm previous results for the equilibrium constant $K$ obtained by one of us by NMR on the DOTP complex, as well as to determine $K$ for a new one with DOTA. Further, we wanted to study and quantify the interactions present in these complexes, with a view to improve them in newly designed complexes.

The interactions between $\gamma$-cyclodextrin and the lanthanide (III)-polyazamacrocyclic chelates, $[\mathrm{Tm}(\mathrm{DOTP})]^{5-}$, and $[\mathrm{Gd}(\mathrm{DOTA})]^{-}$were then studied by isothermal calorimetry (ITC) and molecular dynamics. The calorimetric experiments can be interpreted by considering that in both cases there is a weak association, characterized by low values for the equilibrium constant as well as for the molar enthalpy change for complex formation, at $T=298.15 \mathrm{~K}$. The $K$ value for the complex with DOTP obtained now by ITC is of the same order of magnitude of the one determined previously by NMR. Further, the complex formation seems
\end{abstract}

\footnotetext{
${ }^{*}$ Corresponding author. Tel.: +351-26082811; fax: +351-2026082959.

E-mail address: mbastos@fc.up.pt (M. Bastos).
} 
rather insensitive to the macrocycle, as the values now obtained by ITC for the DOTA complex are very similar to the ones obtained for the DOTP complex.

We have also carried out molecular dynamics simulations on these very same inclusion complexes, which provided quantitative data on the interactions present, as well as a plausible explanation for the data obtained, leading to the proposal of possible solutions to improve the modelling of new contrast agents on a host-guest basis.

(C) 2003 Elsevier Ltd. All rights reserved.

Keywords: Binding equilibria; Titration calorimetry; Molecular dynamics; Lanthanide (III) chelates of polyazamacrocycles; $\gamma$-Cyclodextrin

\section{Introduction}

Magnetic resonance imaging (MRI) is a relatively recent powerful diagnostic tool in clinical practice. The image is mainly due to the nuclear magnetic resonance (NMR) signal of water protons and, as in other tomographies, it is often necessary to increase its sensitivity and tissue specificity. This contrast can be achieved by the administration of suitable paramagnetic agents, and the choice of the proper compound depends on the evaluation of several parameters such as water proton relaxivity, chemical inertness, in vivo toxicity, body distribution, as well as rate and extent of excretion after examination [1,2].

The MRI technique relies heavily on the suitability of contrast agents to enhance the solvent water proton relaxation rates in living tissue. This is the case for some paramagnetic gadolinium (III) chelates, and $\left[\mathrm{Gd}(\mathrm{DOTA}) \cdot\left(\mathrm{H}_{2} \mathrm{O}\right)\right]^{-}$is a good example currently in use. Similar chelates of other lanthanide (III) ions have found also promising applications as paramagnetic shift reagents for in vivo NMR, $[\mathrm{Tm}(\mathrm{DOTP})]^{5-}$ being one of the most effective. Still, there is an ongoing demand for strategies to improve them, and recent research has focussed on the design of new polyazamacrocyclic ligands for the trivalent lanthanide cations of interest, namely DOTA- and DOTP-like derivatives $[3,4]$.

Non-covalent binding of such NMR probes to high molar mass aggregates ought to slow down the rotational dynamics of the whole system and, consequently, optimise the inner-sphere relaxivity [1-4]. Following this line of thought, lanthanide polyazamacrocyclic chelates might form inclusion complexes with cyclodextrins (CDs), thus possibly providing an alternative mechanism whereby the solvent proton relaxation rates and the bio-distribution of these agents could be altered in vivo. This line of investigation has been explored by inclusion of hydrophobic side chains attached to Ln (III) chelates in $\beta$-CD or its oligomers [5-7], and with Ln (III) macrocyclic chelates with $\beta-\mathrm{CD}$ and $\gamma-\mathrm{CD}[8,9]$, but the results of this latter approach have been very disappointing in what concerns the degree of host-guest association $[8,9]$. Given the fact that the design of new contrast agents would undoubtfully benefit from the formation of such $\gamma-\mathrm{CD}$ based adducts, we thought it worthwhile to find out the actual reasons for their unexpected limited success, and whether they could 
be improved. Therefore we have decided to confirm the NMR results by performing isothermal calorimetric experiments (ITC) on the $\left[\mathrm{Ln}(\mathrm{DOTA}) \cdot\left(\mathrm{H}_{2} \mathrm{O}\right)\right]^{-}$and $[\mathrm{Ln}(\mathrm{DOTP})]^{5-}$ inclusion complexes with $\gamma$-cyclodextrin $(\mathrm{Ln} \equiv \mathrm{Gd}, \mathrm{Tm})$ and to carry out molecular dynamics simulations on the same complexes. These later studies have provided us with a plausible explanation for the data obtained. On the whole, our findings have enabled us to propose possible solutions to improve the modelling of new contrast agents based on the host-guest complexes studied.

\section{Experimental}

The $\gamma$-cyclodextrin $(\gamma$-CD) was obtained from Sigma (Sigma, mass fraction purity 0.99 , by HPLC) and kept in a desiccator for a week, over a saturated solution of calcium nitrate (50\% humidity). Under these conditions it does have a well-defined state of hydration, namely, seven water molecules $[10,11]$. The molar mass was thus taken as $1423 \mathrm{~g} \cdot \mathrm{mol}^{-1}$. The DOTP coordination compounds $\left[\mathrm{Na}_{3} \mathrm{H}_{2} \mathrm{Tm}(\mathrm{DOTP}) \cdot 3 \mathrm{NaCl}\right]$ and $\left[\mathrm{Na}_{3} \mathrm{H}_{2} \mathrm{Gd}(\mathrm{DOTP}) \cdot 3 \mathrm{NaCl}\right]$ (where $\mathrm{DOTP} \equiv 1,4,7,10$-tetraazacyclododecane1,4,7,10-tetramethylenephosphonate) were obtained from Magnetic Resonance Solutions, Dallas, TX, USA. As for $\left[\mathrm{NaGd}(\mathrm{DOTA}) \cdot\left(\mathrm{H}_{2} \mathrm{O}\right)\right]$ (where DOTA $\equiv$ 1,4,7,10-tertraazacyclododecane-1,4,7,10-tetraacetate), it was a gift from Guerbet, Aulnay-sous-Bois, France.

All solutions were prepared in volumetric flasks of the desired volume. The water used was distilled and de-ionised, and then filtered through a Milli-Q filtering system. We have observed that the aqueous solutions of $[\text { Tm(DOTP) }]^{5-}$ did not keep stable for very long (a colloidal solution was formed after about $24 \mathrm{~h}$ ). Therefore, all solutions of this chelate were prepared in small volumes, just prior to the calorimetric measurements, and used immediately afterwards; the amount prepared each time was just enough for one (or two) titration(s) and one dilution run. The solutions of $\left[\mathrm{Gd}(\mathrm{DOTA}) \cdot\left(\mathrm{H}_{2} \mathrm{O}\right)\right]^{-}$were stable, and thus an amount of solution enough for at least five titration series was prepared.

The experimental technique used was stepwise Isothermal Titration microCalorimetry (ITC). The water bath and peripheral units were built at Lund University, and a twin heat conduction calorimeter (ThermoMetric, Järfälla, Sweden) was used with a titration cell equipped with a $1 \mathrm{~cm}^{3}$ vessel and a gold stirrer, with a stirring speed of $70 \mathrm{rpm}$. The instrument was calibrated electrically, using an insertion heater $[12,13]$. The cell contained $0.9 \mathrm{~cm}^{3}$ of cyclodextrin solution (concentration $(8-12) \cdot 10^{-3}$ $\left.\mathrm{mol} \cdot \mathrm{dm}^{-3}\right)$ and the titrating solution, an aqueous solution of $[\mathrm{Tm}(\mathrm{DOTP})]^{5-}$ or $\left[\mathrm{Gd}(\mathrm{DOTA}) \cdot\left(\mathrm{H}_{2} \mathrm{O}\right)\right]^{-}$(concentration $\left.(6-9) \cdot 10^{-2} \mathrm{~mol} \cdot \mathrm{dm}^{-3}\right)$, was contained in a $500 \cdot 10^{-3} \mathrm{~cm}^{3}$ gas-tight transformed Hamilton syringe [12]. Each experiment consisted of 15 consecutive injections, of $12.50 \cdot 10^{-3} \mathrm{~cm}^{3}$ each. Dilution effects were taken care of in separate experiments. The binding curves were then corrected for the obtained dilution heats. The experiments were performed at $T=298.15 \mathrm{~K}$ and at least five titration/dilution series were performed for each macrocycle. Both the titration and the calibration experiments were performed in the "fast titration mode", 
and the resulting curves were deconvoluted afterwards with the use of a computer program [14]. The integrals corresponding to each injection were then calculated.

\section{Computational simulations}

The behaviour of the inclusion compounds between $\gamma-\mathrm{CD}$ and either $\left[\mathrm{Gd}(\mathrm{DOTA}) \cdot\left(\mathrm{H}_{2} \mathrm{O}\right)\right]^{-}$or $[\mathrm{Tm}(\mathrm{DOTP})]^{5-}$, in aqueous solution, has been tackled by means of molecular dynamics (MD). Here we present a detailed account of these simulations, introducing first the starting geometries and the parameterisation used, to then focus on the conformational analysis, which took place before performing the simulations in aqueous solution.

\subsection{Starting geometries}

For all DOTA-Ln (III) complexes in solution there are two isomers, major $(M)$ and minor $(m)$, which are observed by NMR spectroscopy in slow exchange at room temperature [15]. Both have a capping water molecule, but whereas isomer $M$ presents a regular square antiprismatic geometry, isomer $m$ adopts an inverted square antiprismatic geometry. For both isomers, we have used the crystallographic structures available in the literature as starting geometries [16-20].

As for [Tm(DOTP) $]^{5-}$, it is known to crystallise in the $m^{\prime}$ form [21], but no crystal structure has been made available so far for any DOTP-Ln (III) complex. Furthermore, the reported LnDOTP-like crystal structures are all $m^{\prime}$ isomers [22], though an NMR study suggests the presence of the $M^{\prime}$ form for the $[\operatorname{Tm}(\mathrm{DOTP})]^{5-}$ complex in solution [8]. These particular structures, $m^{\prime}$ and $M^{\prime}$, are meant to be analogous to the above referred $m$ and $M$ isomers respectively, but without the capping water molecule. Therefore, the $[\operatorname{Tm}(\mathrm{DOTP})]^{5-} m^{\prime}$ structure was modelled [23], after the crystal structures of the complexes with the DOTP-like tetraalkyl-phosphinate ligands [22], DOTMP (1,4,7,10-tetraazacyclododecane1,4,7,10-tetramethylenemethylphosphinate) and DOTBzP (1,4,7,10-tetraazacyclododecane-1,4,7,10-tetramethylenebenzylphosphinate), by substituting the four $\mathrm{R}$ groups $(\mathrm{R} \equiv \mathrm{Bz}, \mathrm{Me})$ by the phosphonate oxygens in DOTP. The $M^{\prime}$ isomer was built based on the NMR structural results [8]. Figure 1 shows a schematic representation of all solution isomers of the chelates under study.

The available crystal structure of the $\gamma$-cyclodextrin $\cdot 12$-crown- $4 \cdot \mathrm{Li}^{+}(3: 1: 1)$ inclusion complex [24], was considered a suitable starting template since the included 12-crown-4 molecule displays a conformation very similar to the tetraaza cycle in the DOTA and DOTP chelates. Accordingly, we used the corresponding $\gamma$-CD crystal coordinates in the model of our host-guest complex structures.

\subsection{Parametrization}

Macromolecular force fields such as CHARMM [25], AMBER [26], or GROMOS [27], do not have parameters for lanthanide high-coordination compounds. 
(a)

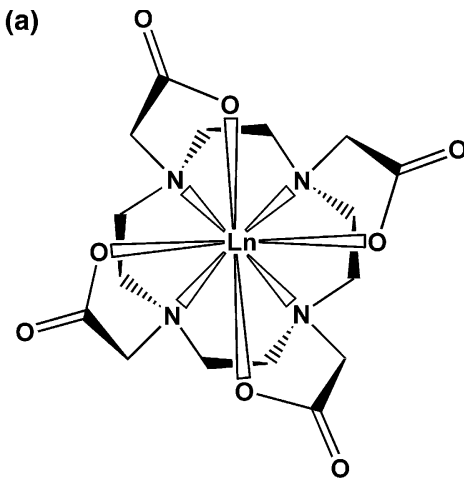

M

(references 16-19)

(b)

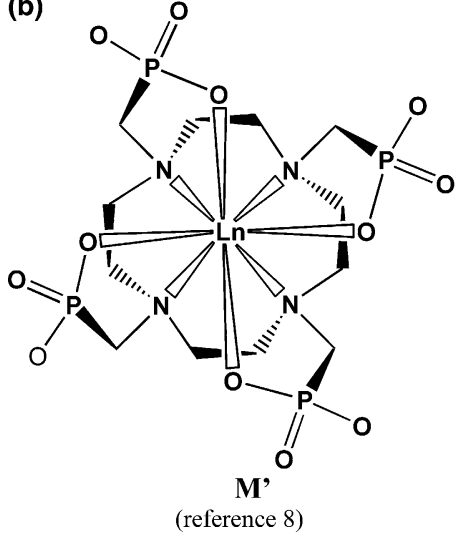

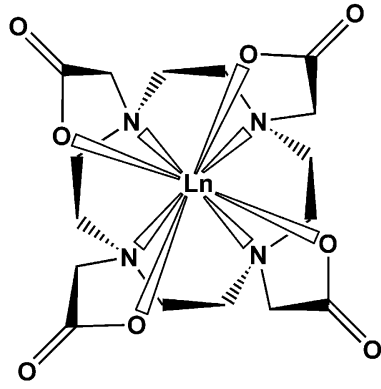

m

(reference 20)

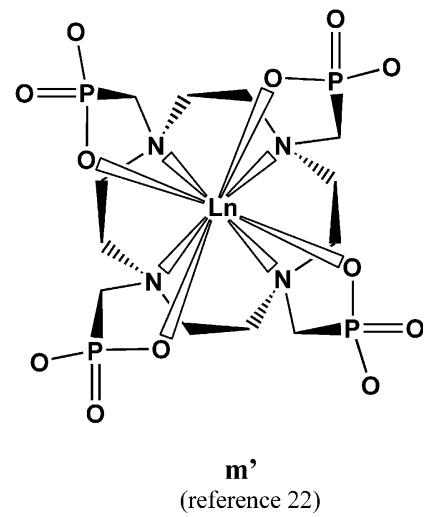

FIGURE 1. Schematic representation of solution structures of the major and minor isomers for (a) $[\mathrm{Gd}(\mathrm{DOTA})]^{-}$and (b) $[\mathrm{Tm}(\mathrm{DOTP})]^{5-}$. The capping water molecule of the DOTA complex has been omitted for visual simplification.

Therefore, we have determined a set of parameters consistent with the CHARMM22 force field, for molecular dynamics simulations of several DOTALn (III) and DOTP-Ln (III) chelates. In order to derive the necessary net atomic charges, we have performed ab initio calculations at the Hartree-Fock level with effective core potentials for the metal ion and the 6-31G* basis set for the ligand atoms; charges were fit to reproduce the molecular electrostatic potential. Geometric parameters were taken from available X-ray structures and NMR studies. Force constants were derived from analogy to existing parameters. All terms followed a heuristic fitting until the CHARMM simulated structures were in good agreement with the experimental ones. Details of the parameterisation have been reported elsewhere $[23,28]$.

The parameterisation of the $\gamma$-CD offered no problems since CHARMM has already been parameterised for oligosaccharides [25]. 


\subsection{Conformational analysis}

We have modelled four host-guest complexes by placing each isomer $(M$ and $m)$ of $\left[\mathrm{Gd}(\mathrm{DOTA}) \cdot\left(\mathrm{H}_{2} \mathrm{O}\right)\right]^{-}$and $\left(M^{\prime}\right.$ and $\left.m^{\prime}\right)$ of $[\mathrm{Tm}(\mathrm{DOTP})]^{5-}$ inside the empty cavity of a $\gamma$-CD molecule. To find out the best fit of each guest inside the host, we first performed appropriate systematic searches using molecular mechanics to energy minimize the different scanned conformations. The resulting four models were to be taken as the starting geometries for the subsequent simulations in aqueous solution.

For each inclusion complex, the initial structure (figure 2) was achieved by placing the chelate at a distance $d$ of $0.27 \mathrm{~nm}$ from the plane defined by the anomeric oxygen atoms of the glucose units of the CD host, as suggested in [7]. This distance, taken from the lanthanide atom of the chelate, was then increased in steps of $0.03 \mathrm{~nm}$ up to $0.51 \mathrm{~nm}$ and then, with larger increments, to $0.70 \mathrm{~nm}, 0.90 \mathrm{~nm}$, $0.120 \mathrm{~nm}, 0.170 \mathrm{~nm}$, and finally $0.210 \mathrm{~nm}$, at which point intermolecular interaction energies become negligible. Simultaneously, the position of the chelate relative to the $\gamma$-CD was rotated by an angle $\alpha$, taken as the angle between the plane defined by two directly opposite $\gamma$-CD anomeric oxygens and the lanthanide atom, and the plane defined by two non-adjacent chelate oxygens bound to the lantha-

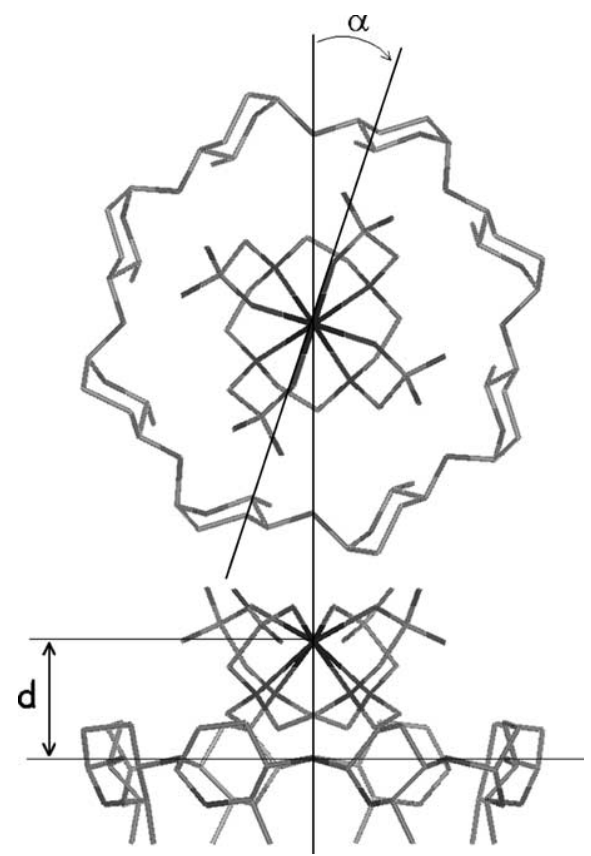

FIGURE 2. Schematic representation (exemplified for a $[\operatorname{Ln}(D O T P)]^{5-}: \gamma-C D$ complex) of the conformational analysis scanned parameters $d$, the host-guest relative distance, and $\alpha$, the host-guest rotational angle. 
nide atom and this latter, in steps of $1^{\circ}$. Figure 2 is a schematic representation of the conformational search parameters $d$ (distance) and $\alpha$ (angle) exemplified for one of the inclusion complexes.

\subsection{Simulations in aqueous solution}

All MD simulations carried out in this work were performed with the computer program CHARMM [25], on alpha-digital EV5 processor (600 $\mathrm{MHz}$ ) workstations.

Both major and minor isomers of the $\left[\mathrm{Gd}(\mathrm{DOTA}) \cdot\left(\mathrm{H}_{2} \mathrm{O}\right)\right]^{-}$and $[\mathrm{Tm}(\mathrm{DOTP})]^{5-}$ complexes with $\gamma$-CD were studied in the canonical ensemble, at $300 \mathrm{~K}$ using the Nosé-Hoover thermostat with a thermal inertia coupling constant of $418 \mathrm{~kJ} \cdot \mathrm{s}^{2}$ and an integration time step of $1 \mathrm{fs}$. SHAKE was used to constrain all bonds involving hydrogens [30]. Each simulation was carried out with the system in a $3.4 \mathrm{~nm}$ cubic box containing 1245 TIP3P equilibrated water molecules [29]. The box was subjected to minimum-image periodic boundary conditions; interactions at distances greater than $1.50 \mathrm{~nm}$ were truncated, the switching turning on and off distances being $1.325 \mathrm{~nm}$ and $1.400 \mathrm{~nm}$, respectively. The four systems were all simulated for a total of $1120 \mathrm{ps}$ each, and trajectories were saved every $0.02 \mathrm{ps}$. An additional run for the free $\gamma$-CD in a $3.4 \mathrm{~nm}$ cubic box with 1262 TIP3P water molecules was also carried out under the same dynamic conditions.

\section{Results}

\subsection{Calorimetry}

The calorimetric results obtained, illustrated in figures 3(a) and (b) for the titration and dilution curves of the $[\operatorname{Tm}(\mathrm{DOTP})]^{5-}: \gamma-\mathrm{CD}$ system, indicate the existence of a weak interaction between the macrocycles $[\operatorname{Tm}(\mathrm{DOTP})]^{5-}$ or $\left[\mathrm{Gd}(\mathrm{DOTA}) \cdot\left(\mathrm{H}_{2} \mathrm{O}\right)\right]^{-}$and $\gamma-\mathrm{CD}$ in aqueous solution. The results were analysed assuming the formation of a 1:1 complex between the macrocycle and $\gamma$-cyclodextrin, as in both cases it was the simplest chemical model that could fit the experimental data. The $K$ and $\Delta_{\mathrm{r}} H_{\mathrm{m}}^{\circ}$ values for the binding reaction were then obtained by treatment of the corrected calorimetric data by the Digitam Software, version 3.0 (Thermometric AB, Sweden, 1995). From the obtained $K$ value, the corresponding $\Delta_{\mathrm{r}} G_{\mathrm{m}}^{\circ}$ value at $T=298.15 \mathrm{~K}$ was calculated. The standard entropy change upon binding at $T=298.15 \mathrm{~K}, \Delta_{\mathrm{r}} S_{\mathrm{m}}^{\circ}$, was calculated from the corresponding $\Delta_{\mathrm{r}} G_{\mathrm{m}}^{\circ}$ and $\Delta_{\mathrm{r}} H_{\mathrm{m}}^{\circ}$ values. The results can be seen in table 1 .

The errors assigned to the $\mathrm{K}$ and $\Delta_{\mathrm{r}} H_{\mathrm{m}}^{\circ}$ values were those provided by the calculation program (square root of the diagonal elements of the variance-covariance matrix). The error for the $\Delta_{\mathrm{r}} G_{\mathrm{m}}^{\circ}$ value was calculated by a propagation of error formula. The error assigned to the $\Delta_{\mathrm{r}} S_{\mathrm{m}}^{\circ}$ value was half the largest interval of possible $\Delta_{\mathrm{r}} S_{\mathrm{m}}^{\circ}$ values obtained from the combined uncertainties in $\Delta_{\mathrm{r}} G_{\mathrm{m}}^{\circ}$ and $\Delta_{\mathrm{r}} H_{\mathrm{m}}^{\circ}$ values. 


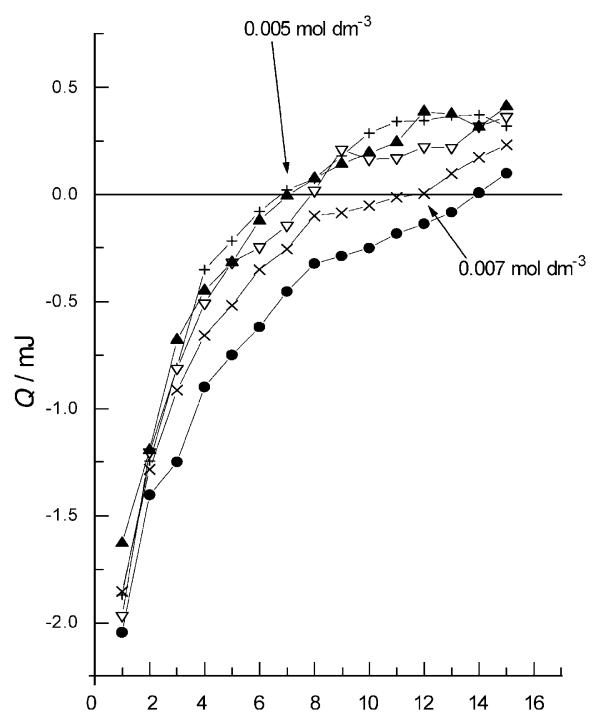

(a)

n. of injections

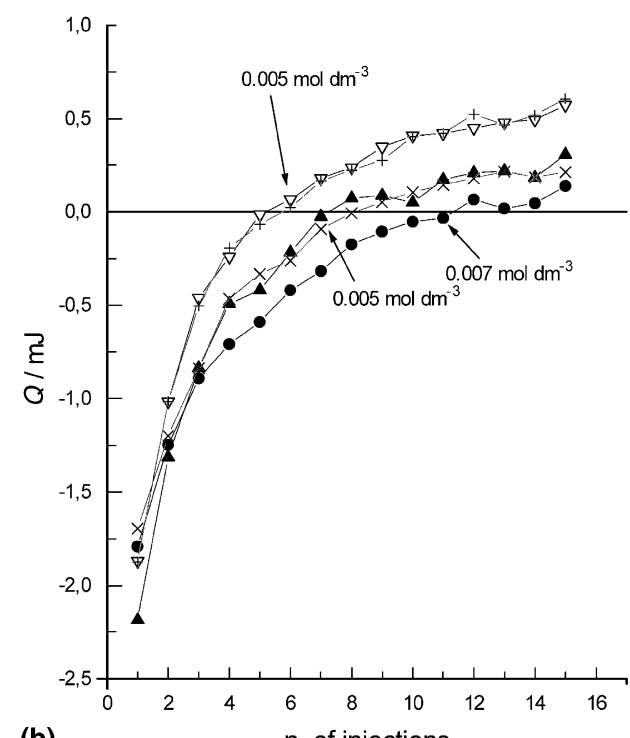

(b)

n. of injections

FIGURE 3. Heat released/adsorbed plotted against the number of injections for (a) titration series of $\gamma$ $\mathrm{CD}$ (concentration $0.008045 \mathrm{~mol} \cdot \mathrm{dm}^{-3}$ ) with solutions of $[\mathrm{Tm}(\mathrm{DOTP})]^{5-}$ of different concentration, and (b) dilution series of the solutions of $[\mathrm{Tm}(\mathrm{DOTP})]^{5-}$ into water: $(\bullet) 0.05036 \mathrm{~mol} \cdot \mathrm{dm}^{-3} ;(\times) 0.05910$ $\mathrm{mol} \cdot \mathrm{dm}^{-3} ;(\Delta) 0.05973 \mathrm{~mol} \cdot \mathrm{dm}^{-3}$; (+) $0.06503 \mathrm{~mol} \cdot \mathrm{dm}^{-3}$; and $(\nabla) 0.06845 \mathrm{~mol} \cdot \mathrm{dm}^{-3}$. The numeric values marked in the figure are the concentrations of $[\mathrm{Tm}(\mathrm{DOTP})]^{5-}$ in the vessel at zero-crossing (see text).

TABLE 1

Thermodynamic parameters for the association of $[\operatorname{Tm}(\mathrm{DOTP})]^{5-}$ and $\left[\mathrm{Gd}(\mathrm{DOTA}) \cdot\left(\mathrm{H}_{2} \mathrm{O}\right)\right]^{-}$with $\gamma$-cyclodextrin, at $T=298.15 \mathrm{~K}$

\begin{tabular}{|c|c|c|c|c|}
\hline & $K$ & $\Delta_{\mathrm{r}} G_{\mathrm{m}}^{\circ}$ & $\Delta_{\mathrm{r}} H_{\mathrm{m}}^{\circ}$ & $\Delta_{\mathrm{r}} S_{\mathrm{m}}^{\circ}$ \\
\hline & & $\overline{\left(\mathrm{kJ} \cdot \mathrm{mol}^{-1}\right)}$ & $\left(\mathrm{kJ} \cdot \mathrm{mol}^{-1}\right)$ & $\overline{\left(\mathrm{J} \cdot \mathrm{K}^{-1} \mathrm{~mol}^{-1}\right)}$ \\
\hline $\begin{array}{l}{[\mathrm{Tm}(\text { DOTP })]^{5_{-}}} \\
{\left[\mathrm{Gd}(\text { DOTA }) \cdot\left(\mathrm{H}_{2} \mathrm{O}\right)\right]^{-}}\end{array}$ & $\begin{array}{l}16 \pm 2 \\
10 \pm 2\end{array}$ & $\begin{array}{l}-6.9 \pm 0.3 \\
-5.7 \pm 0.5\end{array}$ & $\begin{aligned}-3 & \pm 2 \\
-2.2 & \pm 0.4\end{aligned}$ & $\begin{array}{l}13 \pm 8 \\
12 \pm 3\end{array}$ \\
\hline
\end{tabular}

$K$ is the equilibrium constant, $\Delta_{\mathrm{r}} G_{\mathrm{m}}^{\circ}$ is the molar Gibbs free energy change, $\Delta_{\mathrm{r}} H_{\mathrm{m}}^{\circ}$ the molar enthalpy change, and $\Delta_{\mathrm{r}} S_{\mathrm{m}}^{\circ}$ the molar entropy change for the binding equilibria, assuming the formation of a $1: 1$ complex.

\subsection{Conformational analysis}

Shown in figure 4 are the results obtained for the conformational search to find the best fit in the $\left[\mathrm{Gd}(\mathrm{DOTA}) \cdot\left(\mathrm{H}_{2} \mathrm{O}\right)\right]^{-}: \gamma-\mathrm{CD}$ system. Here the intermolecular energy is plotted against the host-guest rotational angle $\alpha$ and the host-guest relative distance $d$. The behaviour of the energy is compatible with the $\mathrm{C}_{8}$ symmetry of the $\gamma-C D$, with the same minimum value repeating itself eight times for each distance. Figure 5 plots that minimum energy value as a function of distance $d$. It is easily observed that the "optimal" distance of $0.27 \mathrm{~nm}$ - as inferred experimentally [8,9], - is 


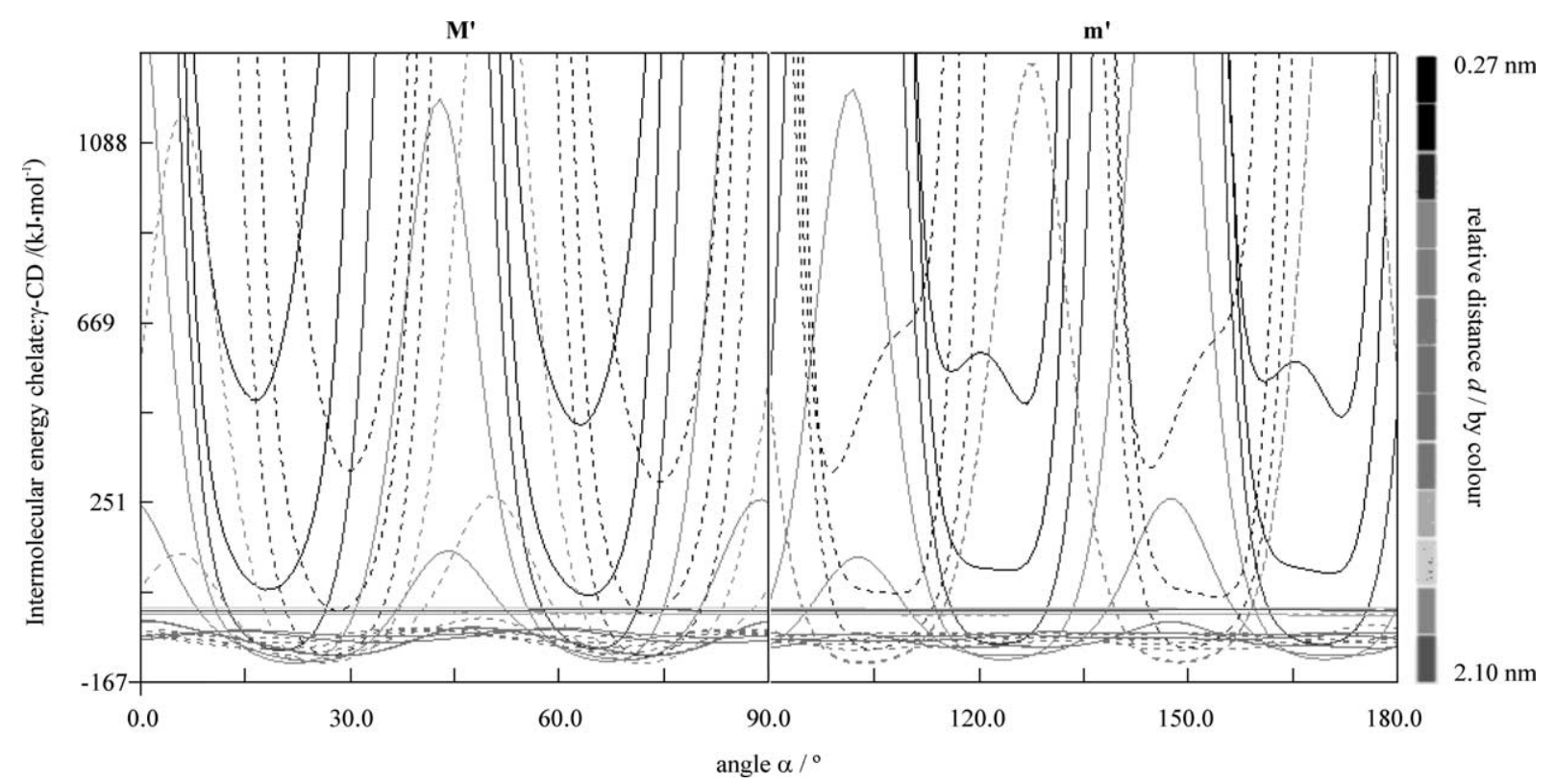

FIGURE 4. Intermolecular energy plotted against the host-guest rotational angle $\alpha$ (for each scanned host-guest relative distance $d$ ), for the $M$ - and $m-\left[\mathrm{Gd}(\mathrm{DOTA}) \cdot\left(\mathrm{H}_{2} \mathrm{O}\right)\right]^{-}: \gamma-\mathrm{CD}$ inclusion complexes. 


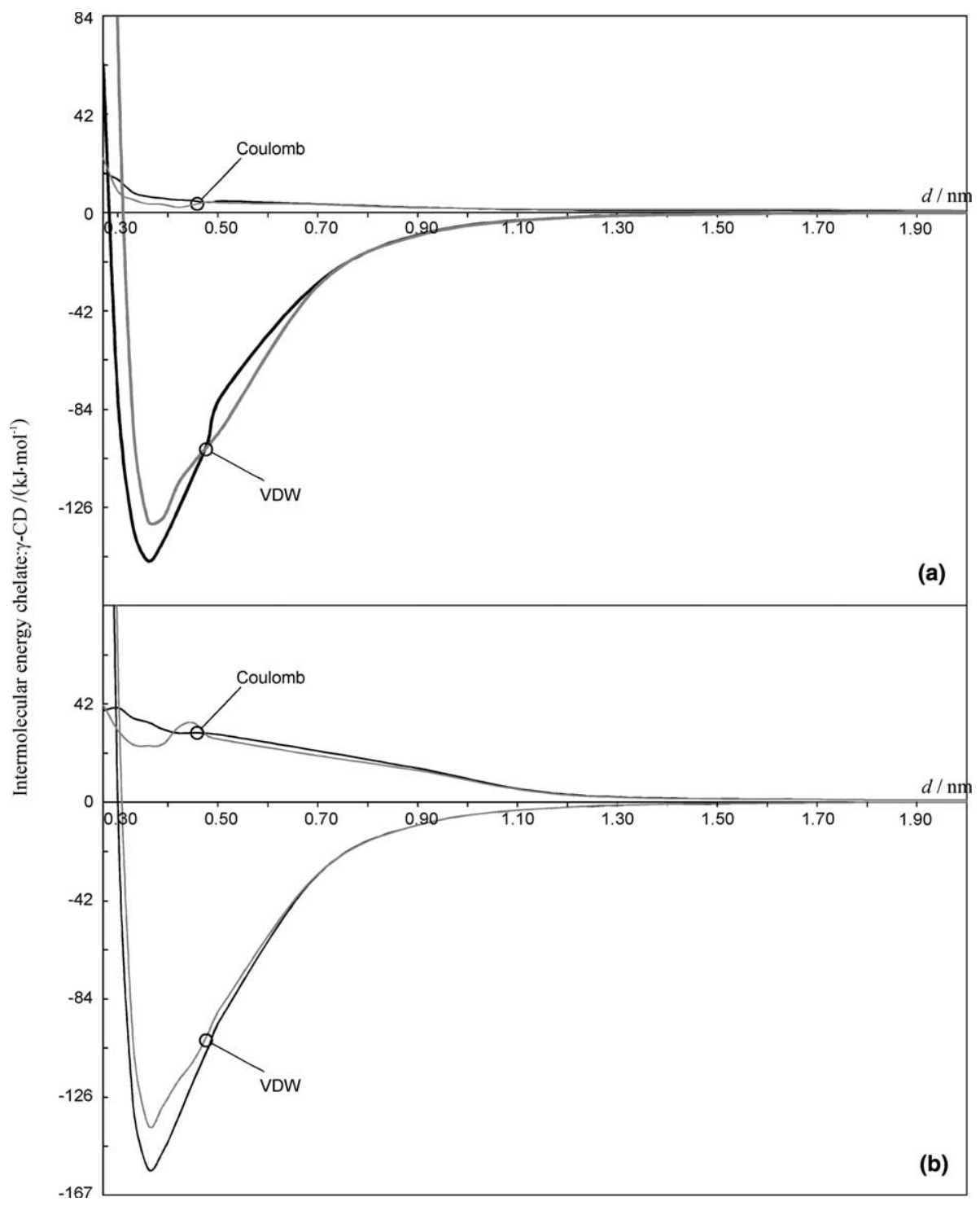

FIGURE 5. Profile of the chelate: $\gamma$-CD VDW and Coulomb interaction potential plotted against separation distance $d$, corresponding to the host-guest intermolecular energy minima determined by scanning of angle $\alpha$ (refer to Fig. 4). (a) $\left[\mathrm{Gd}(\mathrm{DOTA}) \cdot\left(\mathrm{H}_{2} \mathrm{O}\right)\right]^{-}: \gamma-\mathrm{CD}$, and (b) $[\mathrm{Tm}(\mathrm{DOTP})]^{5-}: \gamma-\mathrm{CD}$; isomers major in black and minor in grey.

clearly unfavourable, with a van der Walls (VDW) energy component excessively positive and indicative of bad contacts: particularly serious are those which arise between the aliphatic hydrogens in the interior of the $\gamma$-CD cavity $(\mathrm{H} 3, \mathrm{H} 5$ in figure 7) and the hydrogens of the guest. 
TABLE 2

Host-guest relative distance, $d$, and orientational angle, $\alpha$, values, for the minimum interaction energy structures of the $(M$ and $m)\left[\mathrm{Gd}(\mathrm{DOTA}) \cdot\left(\mathrm{H}_{2} \mathrm{O}\right)\right]^{-}: \gamma-\mathrm{CD}$ and $\left(M^{\prime}\right.$ and $\left.m^{\prime}\right)[\mathrm{Tm}(\mathrm{DOTP})]^{5-}: \gamma-\mathrm{CD}$ complexes

\begin{tabular}{lllcc}
\hline & $M$ & $m$ & $M^{\prime}$ & $m^{\prime}$ \\
\hline$\alpha /^{\circ}$ & 19 & 25 & 18 & 13 \\
$d / \mathrm{nm}$ & 0.360 & 0.360 & 0.360 & 0.360 \\
\hline
\end{tabular}

According to the present conformational analysis, the best fit occurs for a distance $d$ around $0.36 \mathrm{~nm}$ for any of the chelates. Looking into this docking as a function of the chelates common denominator, i.e., the methylene groups, it can be observed that at a distance of $0.36 \mathrm{~nm}$, the four planes defined by the "problematic" hydrogens lie in such a way as to minimize all the possible inclusion bad contacts; host-guest VDW interactions are probably the main contributors to the degree of inclusion of those complexes. Furthermore, the analogous inclusion distance for the $\gamma$-cyclodextrin $\cdot 12$-crown- $4 \cdot \mathrm{Li}^{+}$complex taken as the initial template [24], varies between 0.325 and $0.352 \mathrm{~nm}$, so we would expect an even bigger distance for our bulkier guests.

All the $d$ and $\alpha$ values for the minimum energy results of the four host-guest complexes have been summarized in table 2 , and the starting geometries of all subsequent calculations have been taken according to these values.

\subsection{Simulations in aqueous solution}

\subsubsection{Average structure of free $\gamma-C D$}

We have run an MD simulation of the host free in solution; for the last $400 \mathrm{ps}$, the average value of the root mean square (RMS) deviations of the $\gamma$-CD structure coordinates (heavy atoms) was $(0.10 \pm 0.02) \mathrm{nm}$. We have observed that even though along the simulation there were significant structural fluctuations - the same symmetry breaking reported by Lipkowitz [31], - the RMS of the average MD structure relative to the starting one was only $0.055 \mathrm{~nm}(0.029 \mathrm{~nm}$ if we exclude the rapidly rotating oxygen atoms of the 6-hydroxyl groups). In fact, the superposition of these two structures reveals a good symmetry preservation - almost $\mathrm{C}_{8}$ - that can also be observed even for time averages as low as 100 ps. This result supports our approach

TABLE 3

MD-averaged values (and corresponding standard deviations) for the host-guest relative orientational parameters $d$ and $\alpha$, and for the heavy atoms RMS differences of the host and guest structures relative to the initial ones, calculated for the last $1000 \mathrm{ps}$ of simulation of the $(M$ and $m)\left[\mathrm{Gd}(\mathrm{DOTA}) \cdot\left(\mathrm{H}_{2} \mathrm{O}\right)\right]^{-}: \gamma-\mathrm{CD}$ and $\left(M^{\prime}\right.$ and $\left.m^{\prime}\right)[\operatorname{Tm}(\mathrm{DOTP})]^{5-}: \gamma-\mathrm{CD}$ complexes

\begin{tabular}{lcccc}
\hline & $M$ & $m$ & $M^{\prime}$ & $m^{\prime}$ \\
\hline$\alpha /{ }^{\circ a}$ & 18 & 17 & 17 & 17 \\
$d / \mathrm{nm}$ & $0.37 \pm 0.02$ & $0.40 \pm 0.03$ & $0.38 \pm 0.03$ & $0.37 \pm 0.02$ \\
$\mathrm{RMS}_{\text {chelate }} / \mathrm{nm}$ & $0.016 \pm 0.002$ & $0.019 \pm 0.002$ & $0.026 \pm 0.003$ & $0.020 \pm 0.003$ \\
$\mathrm{RMS}_{\gamma-\mathrm{CD}} / \mathrm{nm}$ & $0.07 \pm 0.01$ & $0.09 \pm 0.02$ & $0.08 \pm 0.01$ & $0.09 \pm 0.01$ \\
\hline
\end{tabular}

\footnotetext{
${ }^{a}$ Calculated for the MD-average structure of each inclusion complex.
} 
in retaining the $\gamma-\mathrm{CD}$ symmetric conformation during the conformational search described above.

\subsubsection{Dynamics and structural properties of the host-guest complexes}

The time averaged values, for $d, \alpha$ and relevant structural RMS deviations, calculated for the last 1000 ps of simulation, are summarized in table 3. Generally speaking, temperature was well conserved throughout the MD simulations, the chelate: $\gamma-\mathrm{CD}$ inclusion distance increased slightly to $c a .0 .4 \mathrm{~nm}$, the angle $\alpha$ acquired a common value of approximately $17^{\circ}$, and the MD average structure for each complex did preserve the original symmetry. The average values for the total and host-guest intermolecular VDW and electrostatic energies are outlined in table 4. For all four inclusion complexes, $\left[\mathrm{Gd}(\mathrm{DOTA}) \cdot\left(\mathrm{H}_{2} \mathrm{O}\right)\right]^{-}: \gamma-\mathrm{CD}(M$ and $m)$ and $[\mathrm{Tm}(\mathrm{DOTP})]^{5-}: \gamma-\mathrm{CD}\left(M^{\prime}\right.$ and $\left.m^{\prime}\right)$, figure 6 displays the host-guest (inter) nonbonding potential energies as a function of simulation time.

TABLE 4

Average values for the total nonbonding van der Waals (VDW) and electrostatic (elec) energies, and for the intermolecular (host-guest $\equiv \mathrm{h}-\mathrm{g}$ ) van der Waals $\left(\mathrm{VDW}_{\mathrm{h}-\mathrm{g}}\right)$ and electrostatic $\left(\mathrm{elec}_{\mathrm{h}-\mathrm{g}}\right)$ energies, relative to the MD simulations of the $(M$ and $m)\left[\mathrm{Gd}(\mathrm{DOTA}) \cdot\left(\mathrm{H}_{2} \mathrm{O}\right)\right]^{-}: \gamma-\mathrm{CD}$ and $\left(M^{\prime}\right.$ and $\left.m^{\prime}\right)$ $[\mathrm{Tm}(\mathrm{DOTP})]^{5-}: \gamma-\mathrm{CD}$ complexes

\begin{tabular}{lcccc}
\hline & \multicolumn{1}{c}{$m$} & \multicolumn{1}{c}{$M^{\prime}$} & \multicolumn{1}{l}{$m^{\prime}$} \\
\hline $\mathrm{VDW} / \mathrm{kJ} \cdot \mathrm{mol}^{-1}$ & $4560 \pm 88$ & $4560 \pm 88$ & $4519 \pm 92$ & $4477 \pm 92$ \\
$\mathrm{VDW}$ & $-130 \pm 11$ & $-138 \pm 8$ & $-146 \pm 8$ & $-125 \pm 13$ \\
$\mathrm{elec} / \mathrm{kJ} \cdot \mathrm{mol}^{-1}$ & $-58,953 \pm 176$ & $-58,911 \pm 184$ & $-59,413 \pm 184$ & $-59,371 \pm 184$ \\
$\mathrm{elec}_{\mathrm{h}-\mathrm{g}} / \mathrm{kJ} \cdot \mathrm{mol}^{-1}$ & $-54 \pm 23$ & $-21 \pm 20$ & $-418 \pm 96$ & $-251 \pm 63$ \\
\hline
\end{tabular}

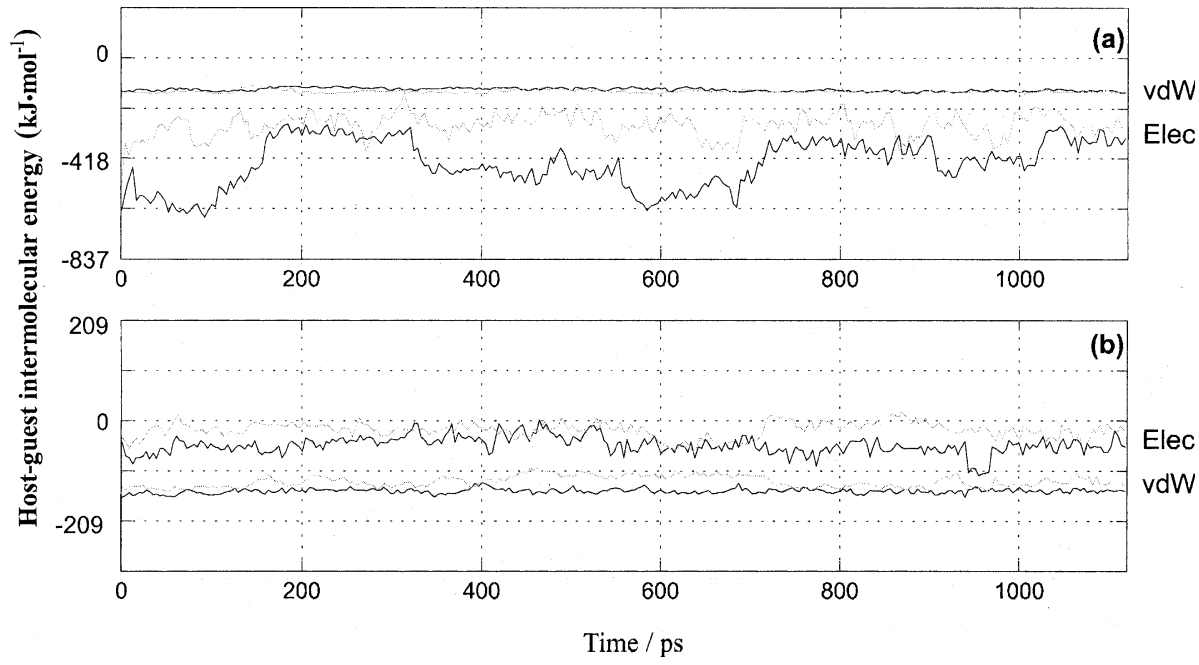

FIGURE 6. The van der Waals and electrostatic intermolecular (host-guest) energies plotted against time for (a) $M^{\prime}-[\mathrm{Tm}(\mathrm{DOTP})]^{5-}: \gamma-\mathrm{CD}$ (black line), $m^{\prime}-[\mathrm{Tm}(\mathrm{DOTP})]^{5-}: \gamma-\mathrm{CD}$ (grey line) and (b) $M-\left[\mathrm{Gd}(\mathrm{DOTA}) \cdot\left(\mathrm{H}_{2} \mathrm{O}\right)\right]^{-}: \gamma-\mathrm{CD}$ (black line), $m-\left[\mathrm{Gd}(\mathrm{DOTA}) \cdot\left(\mathrm{H}_{2} \mathrm{O}\right)\right]^{-}: \gamma-\mathrm{CD}$ (grey line). 


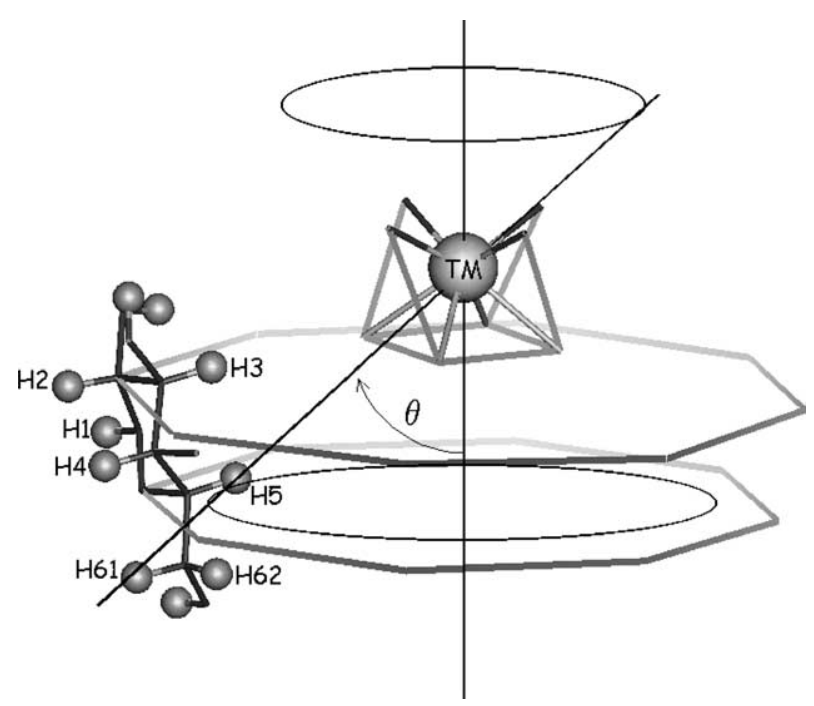

FIGURE 7. Schematic representation of the axial symmetry model used in the calculation of lanthanideinduced shifts, LIS $=D\left(3 \cos ^{2} \theta-1\right) / r^{3}, r$ being the lanthanide-proton distance.

Lanthanide-induced shifts (LIS) for the $\gamma$-CD protons were also determined assuming a pseudo-contact shift model with axial symmetry [9], as shown in the scheme of figure 7. The LIS values relative to $\mathrm{H} 2$ were then calculated on the basis of the MD average geometry of the adducts (which hold the same $d$ values presented in table 3) and compared to those obtained experimentally [8,9]; the relevant results are summarised in table 5. The LIS values derived from the MD structural results proved useful to confirm that the geometries of the host-guest complexes had been properly determined. As can be seen from the analysis of table 5, the calculated values for $[\mathrm{Tm}(\mathrm{DOTP})]^{5-}$ are in very good agreement with the experimental ones, except for the H61 and H62 protons, which are less well reproduced. In fact, it must be difficult to reproduce them correctly, since the rapid rotation about the $\mathrm{C} 5-\mathrm{C} 6$ bonds of the glucose units, which seems to exist in solution, assigns fuzzy average positions in space to these particular protons. Actually, methods used to fit the NMR experimental results seem to have the same problem in reproducing these particular values [8]. However, we have recalculated these two values - for H61 and $\mathrm{H} 62$-, after redefining the geometry according to a possible $\mathrm{C}_{4}$ symmetry conformation adopted by the eight $\mathrm{CH}_{2} \mathrm{OH}$ groups (dihedrals $\mathrm{C} 4-\mathrm{C} 5-\mathrm{C} 6-\mathrm{O} 6$ ) of the lower rim of the $\gamma$-CD [31]. The resulting values are also shown in table 5 between brackets; curiously enough they are in much better agreement with the experimental ones, suggesting that this could be a preferred conformation in solution. This made us carry out a more detailed analysis of the dynamics evolution of the above referred dihedrals C4-C5-C6-O6, that has shown two almost equally probable values for that dihedral, lying between $70^{\circ}-80^{\circ}$ and $150^{\circ}-160^{\circ}$, which makes the $\mathrm{C}_{4}$ symmetry one of the possible arrangements. 
TABLE 5

Experimental and calculated lanthanide-induced shifts, $\operatorname{LIS}^{a}$ (in ppm) relative to $\mathrm{H} 2$, for all inclusion complexes

\begin{tabular}{|c|c|c|c|c|c|c|}
\hline \multirow[t]{3}{*}{ Proton } & \multicolumn{3}{|c|}{$[\mathrm{Tm}(\mathrm{DOTP})]^{5-}: \gamma-\mathrm{CD}$} & \multicolumn{3}{|c|}{$\left[\mathrm{Gd}(\mathrm{DOTA})\left(\mathrm{H}_{2} \mathrm{O}\right)\right]^{-}: \gamma-\mathrm{CD}$} \\
\hline & \multirow{2}{*}{$\begin{array}{l}\text { Experimental }[8] \\
\text { LIS ( } 1: 1 \text { complex) }\end{array}$} & \multicolumn{2}{|c|}{ Calculated LIS } & \multirow{2}{*}{$\begin{array}{l}\text { Fitted NMR [9] } \\
\left.\text { LIS (1:1 complex }{ }^{b}\right)\end{array}$} & \multicolumn{2}{|c|}{ Calculated LIS } \\
\hline & & $\overline{M^{\prime}}$ & $m^{\prime}$ & & $M$ & $m$ \\
\hline H1 & -0.46 & -0.45 & -0.43 & -0.74 & -0.47 & -0.39 \\
\hline $\mathrm{H} 2$ & -1.00 & -1.00 & -1.00 & -1.00 & -1.00 & -1.00 \\
\hline H3 & -2.41 & -2.23 & -2.67 & -3.69 & -2.38 & -2.13 \\
\hline $\mathrm{H} 4$ & -0.46 & -0.44 & -0.41 & -0.75 & -0.47 & -0.35 \\
\hline H5 & 1.69 & 1.73 & 1.88 & 0.41 & 1.68 & 2.20 \\
\hline H61 & 1.19 & 0.49 & 0.61 & 1.30 & 1.51 & 1.88 \\
\hline (H61) & - & $(0.90)$ & $(0.86)$ & - & $(0.94)$ & $(1.21)$ \\
\hline H62 & 0.95 & 1.45 & 1.81 & 0.94 & 0.49 & 0.68 \\
\hline (H62) & - & $(0.95)$ & (1.08) & - & $(0.64)$ & $(0.89)$ \\
\hline
\end{tabular}

${ }^{a}$ LIS $=D\left(3 \cos ^{2} \theta-1\right) / r^{3}$; the actual value of the magnetic proportionality constant $(D)$ is not needed when taking a proton $(\mathrm{H} 2)$ as reference.

${ }^{b}[\mathrm{Tm}(\mathrm{DOTA})]^{-}: \gamma-\mathrm{CD}$.

Table 5 also includes the calculated hypothetical LIS values for the MD averaged structure of the $\left[\mathrm{Gd}(\mathrm{DOTA}) \cdot\left(\mathrm{H}_{2} \mathrm{O}\right)\right]^{-}: \gamma-\mathrm{CD}$ complex. They can be loosely compared to the NMR-derived LIS values fitted for a 1:1 [Tm(DOTA) $]^{-}: \gamma-\mathrm{CD}$ complex, which are available in the literature [9]. The LIS values are relatively different, but then, apart from the fact that the lanthanide is not the same in both cases, one has to consider that for the $[\mathrm{Tm}(\mathrm{DOTA})]^{-}: \gamma-\mathrm{CD}$ complex the hypothesis of the parallel formation of a 2:1 adduct was put forward [9], with the two adducts (1:1 and 2:1) adjusted to an inclusion distance $d$ of only $0.27 \mathrm{~nm}$. As mentioned previously, our modelling studies portray a significantly larger value for this key distance (nearer $0.4 \mathrm{~nm}$, see table 4) while discarding the shorter values (e.g., $0.27 \mathrm{~nm}$ ) on the basis of stereochemical hindrance. Predictably, this will affect the fittings to the NMR experimental results and any other findings deriving from them.

Finally, we have calculated the number of H-bonds, host-guest and internal in the $\gamma-\mathrm{CD}$, with the maximum distance between the polar hydrogen and the accepting atom taken as $0.25 \mathrm{~nm}$. The most probable values found were 2 (host-guest) and $16\left(\mathrm{CD}\right.$-intra) in $\left[\mathrm{Gd}(\mathrm{DOTA}) \cdot\left(\mathrm{H}_{2} \mathrm{O}\right)\right]^{-}: \gamma-\mathrm{CD}$, and 5 and 16 in $[\mathrm{Tm}(\mathrm{DOTP})]^{5-}: \gamma-\mathrm{CD}$, irrespective of which isomer we were considering. Figure 8 shows the evolution in time of $\mathrm{H}$-bonds for the two major chelates.

\section{Discussion}

The ITC experiments allowed the calculation of both $\mathrm{K}$ and $\Delta_{\mathrm{r}} H_{\mathrm{m}}^{\circ}$ values for the binding equilibria. Some of the titration and dilution curves obtained for of the $[\mathrm{Tm}(\mathrm{DOTP})]^{5-}: \gamma-\mathrm{CD}$ association are presented in figures $3(\mathrm{a})$ and (b), respectively. The titration curve presents a somewhat unusual profile, as it shows an initial heat 


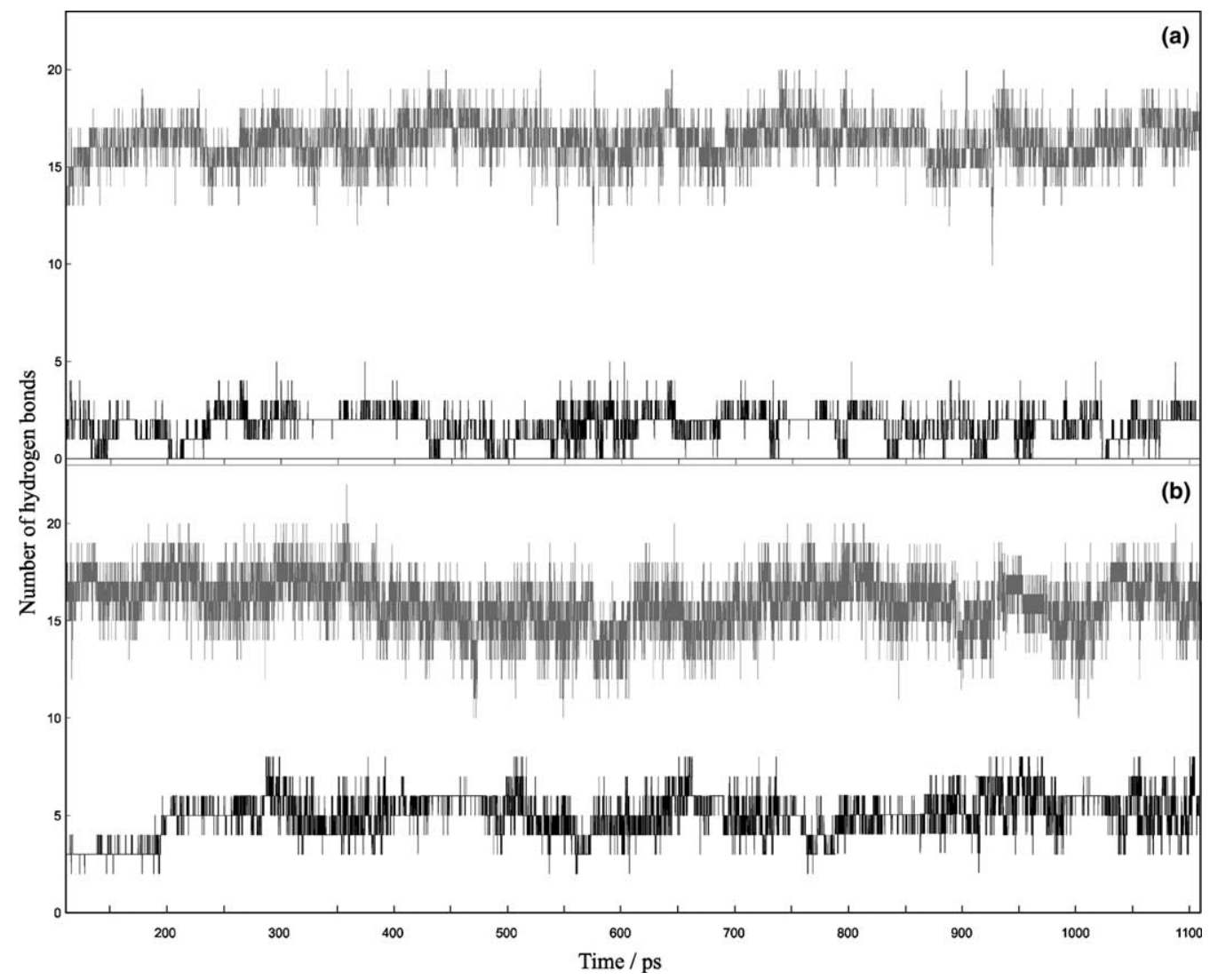

FIGURE 8. Number of host-guest intermolecular H-bonds (in black) and internal of the $\gamma$-CD (in grey) plotted against simulation time, for isomers major $\left(M\right.$ or $\left.M^{\prime}\right)$ of the inclusion complexes (a) $\left[\mathrm{Gd}(\mathrm{DOTA}) \cdot\left(\mathrm{H}_{2} \mathrm{O}\right)\right]^{-}$and (b) $[\mathrm{Tm}(\mathrm{DOTP})]^{5-}$. Instant values are taken every 100 steps. 
release, but then endothermic peaks arise as we progress in the number of injections (figure 3(a)). Since we do the dilution experiments separately when using our titration system, we could see that this effect comes from the dilution of $[\operatorname{Tm}(\mathrm{DOTP})]^{5-}$ (figure 3(b)). The corrected heats (difference between titration and dilution heats) are always negative throughout all titration. Considering that the various titration and dilution curves plotted correspond to experiments with varying initial concentration of $[\operatorname{Tm}(\mathrm{DOTP})]^{5-}$, we thought it important to calculate the actual concentration of $[\mathrm{Tm}(\mathrm{DOTP})]^{5-}$ at the zero-crossing point of each dilution curve: a value of $c a .0 .005$ $\mathrm{mol} \cdot \mathrm{dm}^{-3}$ was found in all cases. It is clear that the initial exothermic dilution, at low $[$ Tm(DOTP $)]^{5-}$ concentrations, becomes endothermic once a certain concentration value is reached. While the exothermic dilution was to be expected, since we have charged species in aqueous solution, the unusual endothermic interaction observed above a critical concentration can be due to the tendency of this complex to aggregate in aqueous solution [32]. This might be the reason for the instability of the $[\operatorname{Tm}(\mathrm{DOTP})]^{5-}$ solutions that we have observed, as in previous NMR studies, where much lower concentrations were used, no such behaviour occurs [8]. Furthermore, in the $\left[\mathrm{Gd}(\mathrm{DOTA}) \cdot\left(\mathrm{H}_{2} \mathrm{O}\right)\right]^{-}$case, where the solutions were stable, the dilution profile was ordinary.

The thermodynamic parameters derived from the corrected heats show that a weak binding takes place between both macrocycles and $\gamma-\mathrm{CD}$ in aqueous solution. The equilibrium constant obtained by calorimetry for $[\operatorname{Tm}(\mathrm{DOTP})]^{5-}, K=16 \pm 2$, is of a similar magnitude of the ones previously obtained for by NMR [8], $K=4.5 \pm 0.2$ and $3.9 \pm 0.1$, from the LIS values for $\mathrm{H} 5$ and $\mathrm{H} 3$, respectively. In fact, with such a weak association, we can consider there is a fair agreement between the $K$ values determined by the two techniques.

As for the $\left[\mathrm{Gd}(\mathrm{DOTA}) \cdot\left(\mathrm{H}_{2} \mathrm{O}\right)\right]^{-}$association with $\gamma-\mathrm{CD}$, the ITC-derived thermodynamic parameters are very similar to the ones obtained for $[\operatorname{Tm}(\mathrm{DOTP})]^{5-}$. The two inclusion complexes are stable, and the binding, although weak, is favourable both enthalpically and entropically (see table 1). This is not surprising as we are dealing with complexes where only dispersive forces are acting, and in that respect the two macrocyclic chelates are not very different: the very MD simulations depict a striking similarity in their docking positions inside the $\gamma$-CD.

The analysis of the MD simulation results also shows a weak association between the Ln (III) polyazamacrocycles and the $\gamma$-CD. For all the inclusion complexes, we first noticed that while the intermolecular VDW energies remain equilibrated during the whole simulation, the electrostatic energies, $\mathrm{elec}_{\mathrm{h}-\mathrm{g}}$, vary hugely (refer to figure 6). Next we observed that the relative host-guest distance is clearly insensitive to these large electrostatic fluctuations, judging from the $d$ values and corresponding RMS in table 3. On the other hand, the structural deviations for $\gamma$-CD in the host-guest complexes (see table 3 ) are considerably large and virtually equivalent to the ones registered for this host free in solution $(0.10 \pm 0.02) \mathrm{nm}$. It seems logical to assume that the degree of inclusion of the chelates in the $\gamma-C D$ is primarily determined by the VDW interactions, without any major constraints imposed on the host's flexibility. Considering that the chelates barely enter the cyclodextrin cone, just as in the case of the conformational search best fits, those VDW interactions might be taken as 
a measure of the steric hindrance between the bulky tetraazamacrocycle and the $\gamma$ CD hydrophobic cavity.

One possible explanation for the above mentioned huge electrostatic fluctuations could be related to the considerable flexibility of the $\gamma-C D$ around the poorly included chelate(s) In fact, not only does the gross structural reorganisation reported by Lipkowitz occur [31], but also do we see significant deviations from the perpendicular in the angle formed between the chelate(s) principal axis and the plane of the $\gamma$-CD anomeric oxygens (which can actually be observed if we look at the dynamics animation). Notice that the guest structures are almost nonflexible (refer to the corresponding relatively small RMS values in table 3), as predicted by Henriques et al. [23]. Consequently, the distances between the cyclodextrin hydroxyl groups and the chelate charged oxygens vary significantly under dynamic conditions, and that should account for most of the electrostatic energy fluctuations. Indeed, some correlation could be found between the elec $_{\mathrm{h}-\mathrm{g}}$ energy and the structural deviations (instantaneous RMS fluctuations) of the $\gamma-\mathrm{CD}$ but the system is far too complex for a unique (linear) correlation to be found between a single structural/orientational parameter and the elec $_{\mathrm{h}-\mathrm{g}}$ energy, as we will see next.

One other factor that must surely contribute to the $\mathrm{elec}_{\mathrm{h}-\mathrm{g}}$ energy fluctuations is the set of host-guest intra and intermolecular hydrogens bonds which form/break in time, presented in figure 8. From their detailed analysis we have established that the $\gamma$-CD preserves the "traditional" intramolecular ring of $\mathrm{H}$-bonds between the 2and 3-hydroxyl groups [33], these groups being also responsible for the formation of $\mathrm{H}$-bonds with the paramagnetic chelate(s). A second set of internal H-bonds occurs, between the 6-hydroxyl groups of adjacent glucoses, resulting from the $\gamma$-CD symmetry loss. The fact that the number of all those H-bonds oscillates substantially in time (this is clear from figure 8) must be another expression of the unrestrained flexibility of the cyclodextrin in the systems under study, and hence buried in the profile of the electrostatic host-guest interaction.

Finally we should comment on the different average number of $\mathrm{H}$-bonds occurring between each of the chelates and the host, 2 for $\left[\operatorname{Gd}(\text { DOTA }) \cdot\left(\mathrm{H}_{2} \mathrm{O}\right)\right]^{-}$and 5 for $[\operatorname{Tm}(\mathrm{DOTP})]^{5-}$. Funnily enough, the higher number of $\mathrm{H}$-bonds found for the DOTP complex is not a consequence of this chelate having twice the number of acceptor oxygen atoms, for only four of them are actually engaged in those H-bonds; it is rather the fact that these four oxygens end up positioned nearer the 2- and 3hydroxyl groups of the $\gamma$-CD than the analogous DOTA ones. This results in one same DOTP-oxygen atom forming two $\mathrm{H}$-bonds rather than a single one, which might be one of the reasons why the association constants are slightly higher for the $[\mathrm{Tm}(\mathrm{DOTP})]^{5-}: \gamma-\mathrm{CD}$ complex.

All things considered, even without a thorough assessment of the solvation and entropic effects, everything seems to point out to the conclusion that the weak association constants result from a stereochemical incompatibility between the $\gamma-C D$ and the chelates under study. One way of overcoming this problem could be the substitution of some groups, in either the chelate or the $\gamma-\mathrm{CD}$, by others that promote a more effective inclusion and stronger interactions between the two molecules. While the first approach has been pursued with some success for adducts of $\beta-C D$ [5-7], 
preliminary results from on-going modelling studies on substituted $\gamma$-CDs show that this can be indeed the case. In fact, and as an example, we have found out that both the ammonium and the trimethylammonium ions acting as substituents for selected groups of the CDs, have good association energies. There are many other substitutions, which will improve the interactions between the host and the guest. The basic problem in the association is that the cross-section of the $\gamma$-CD is too small to accommodate the ligand. As we see it, there are two ways of solving the problem - using larger CDs, or introducing substitutions in the ligand and/or in the $\gamma$-CD in order to increase the interactions with the ligand. We have ruled out the first idea because larger CDs, e.g. $\gamma$-CDs, are expensive and have a tendency to distort into an "eight" shape in aqueous solution, precluding association. We have also discarded the possibility of carrying out substitutions in the ligand for fear of provoking dissociation in the lanthanide, which would have disastrous results. There remained the introduction of substitutions in the $\gamma-\mathrm{CD}$; we have in fact performed a great number of these with excellent results concerning the association between the substituted $\gamma$-CDs and the ligand [34].

\section{Acknowledgements}

We thank the Fundação para a Ciência e Tecnologia (Praxis PCEX/C/QUI/67/96) for their financial support, and Guerbet, S.A., Aulnay-sous-Bois, France, for a sample of $\left[\mathrm{NaGd}(\right.$ DOTA $\left.)\left(\mathrm{H}_{2} \mathrm{O}\right)\right]$. E.S.H. thanks the Fundação para a Ciência e Tecnologia for a research grant (PRAXIS XXI/BD/5103/95). M.J.R. thanks the National Foundation for Cancer Research (NFCR) for financial support.

\section{References}

[1] R.B. Lauffer, Chem. Rev. 87 (1987) 901.

[2] M.F. Tweedle, in: J.-C.G. Bünzli, G.R. Choppin (Eds.), Lanthanide Probes in Life, Chemical and Earth Sciences, Elsevier, Amsterdam, 1989, Chapter 5.

[3] J.A. Peters, J. Huskens, D.J. Raber, Progr. NMR Spectrosc. 28 (1996) 283.

[4] P. Caravan, J.J. Ellison, T.J. McMurry, R.B. Lauffer, Chem. Rev. 99 (1999) 2293.

[5] S. Aime, M. Botta, M. Panero, M. Giandi, F. Uggeri, Magn. Reson. Chem. 29 (1991) 923.

[6] S. Aime, M. Botta, L. Frullano, S. Geninatti Crich, G.B. Giovenzana, R. Pagliarin, G. Palmisano, M. Sisti, Chem. Eur. J. 5 (1999) 1253.

[7] S. Aime, E. Gianolio, E. Terreno, G.B. Giovenzana, R. Pagliarin, M. Sisti, G. Palmisano, M. Botta, M.P. Lowe, D. Parker, J. Biol. Inorg. Chem. 5 (2000) 488.

[8] A.D. Sherry, R. Zarzycki, C.F.G.C. Geraldes, Magn. Res. Chem. 32 (1994) 361.

[9] E. Zitha-Bovens, H. van Bekkum, J.A. Peters, C.F.G.C. Geraldes, Eur. J. Inorg. Chem. (1999) 287.

[10] Handbook of Chemistry and Physics, (E-42), 70th edition, CRC Press, Boca Raton, FL, 1980.

[11] M. Bastos, L.-E. Briggner, I. Shehatta, I. Wadsö, J. Chem. Thermodynamics 22 (1990) 1181.

[12] L.-E. Briggner, I. Wadsö, J. Biochem. Biophys. Methods 22 (1991) 101.

[13] M. Bastos, M. Afonso, M.H.M. Caçote, M.J. Ramos, J. Chem. Soc. Faraday Trans. 93 (1997) 2061.

[14] M. Bastos, S. Hägg, P. Lönnbro, I. Wadsö, J. Biochem. Biophys. Methods 23 (1991) 255.

[15] S. Aime, M. Botta, M. Fasano, M.P. Marques, C.F.G.C. Geraldes, D. Pubanz, A.E. Merbach, Inorg. Chem. 36 (1997) 2059. 
[16] M.-R. Spirlet, J. Rebizant, J.F. Desreux, M.-F. Loncin, Inorg. Chem. 23 (1984) 359.

[17] J.-P. Dubost, J.-M. Leger, M.-H. Langlois, D. Meyer, M. Schaefer, C.R. Acad. Sci. Paris, Ser. 2312 (1991) 349.

[18] C.A Chang, L.C. Francesconi, M.F. Malley, K. Kumar, J.Z. Gougoutas, M.F. Tweedle, Inorg. Chem. 32 (1993) 3501.

[19] S. Aime, A. Barge, M. Botta, M. Fasano, J.D. Ayala, G. Bombieri, Inorg. Chim. Acta 246 (1996) 423.

[20] S. Aime, A. Barge, F. Benetollo, G. Bombieri, M. Botta, F. Uggeri, Inorg. Chem. 36 (1997) 4287.

[21] E.F. Paulus, P. Juretschke, J. Lang, 3 Jarestag der Deutschen Gesellschaft für Kristallographie, Darmstadt, 1995.

[22] S. Aime, A.S. Batsanov, M. Botta, J.A.K. Howard, D. Parker, K. Senanayake, G. Williams, Inorg. Chem. 33 (1994) 4696.

[23] E.S. Henriques, M. Bastos, C.F.G.C. Geraldes, M.J. Ramos, Int. J. Quantum Chem. 73 (1999) 237.

[24] S. Kamitori, K. Hirotsu, T. Higuchi, J. Am. Chem. Soc. 109 (1987) 2409.

[25] A.D. MacKerell Jr., J.K. Wiorkiewicz, M. Karplus, J. Am. Chem. Soc. 117 (1995) 11946;

A.D. McKerell Jr., D. Bashford, M. Bellot, R.L. Dunbrack Jr., Evanseck, M.J. Field, S. Fischer, J. Gao, H. Guo, S. Ha, D. Joseph, L. Kuchnir, K. Kuczera, F.T.K. Lau, C. Mattos, S. Michnick, T. Ngo, D.T. Nguyen, B. Prodhom, W.E. Reiher III, B. Roux, M. Schlenkrich, J. Smith, R. Stote, J. Straub, M. Watanabe, J. Wiorkiewicz-Kuczera, D. Yin, M. Karplus, J. Phys. Chem. B 102 (1998) 3586 ;

A.D. MacKerell Jr., B. Brooks, C.L. Brooks III, L. Nilsson, B. Roux, Y. Won, M. Karplus, in: P.v.R. Schleyer et al. (Eds.), The Encyclopedia of Computational Chemistry, Vol. 1, Wiley, Chichester, 1998, p. 271.

[26] W.D. Cornell, P. Cieplak, C.I. Bayly, I.R. Gould, K.M. Merz Jr., D.M. Ferguson, D.C. Spellmeyer, T. Fox,, J.W. Calwell, P.A. Kollman, J. Am. Chem. Soc. 117 (1995) 5179.

[27] J. Hermans, H.J.C. Berendsen, W.F. Van Gunsteren, J.P.M. Postma, Biopolymers 23 (1984) 1513.

[28] E.S. Henriques, C.F.G.C. Geraldes, M.J. Ramos, Mol. Phys., in press.

[29] W.L. Jorgensen, J. Chandrasekhar, J.D. Madura, R.W. Impey, M.L. Klein, J. Chem. Phys. 79 (1983) 926.

[30] J.P. Ryckaert, G. Ciccotti, H.J.C. Berendsen, J. Comp. Phys. 23 (1977) 327.

[31] K.B. Lipkowitz, J. Org. Chem. 56 (1991) 6357.

[32] C.F.G.C. Geraldes, R.D. Brown, III, W.P. Cacheris, S.H. Koenig, A.D. Sherry, M. Spiller, Magn. Reson. Med. 9 (1989) 94.

[33] K.B. Lipkowitz, Chem. Rev. 98 (1998) 1829.

[34] P.A. Fernandes, A.T.P. Carvalho, A.T. Marques, A.L.F. Pereira, A.P.S. Madeira, A.S.P. Ribeiro, A.F.R. Carvalho, E.T.A. Ricardo, F.J.V. Pinto, H.A. Santos, H.D.G. Mangericão, H.M. Martins, H.D.B. Pinto, H.R.R. Santos, I.S. Moreira, M.J.V. Azeredo, R.P.S. Abreu, R.M.S. Oliveira, S.F.M. Sousa, R.J.A.M. Silva, Z.S. Mourão, M.J. Ramos, J. Comp.-Aided Mol. Design, 2003, in press.

JCT $03 / 044$ 